\title{
How Tax Reduction or Exemption Influence Prices -- Empirical Evidence from Cases About Tampon Tax Reduction or Exemption
}

\author{
Siyu Pan ${ }^{1}$; Xintian Zhou ${ }^{2}$; Szeying Chan \\ ${ }^{1}$ Suzhou High School of Jiangsu Province, Suzhou, Jiangsu, 215021, China \\ ${ }^{2}$ United World College Changshu China, Suzhou, Jiangsu, 215500, China \\ ${ }^{3}$ Dulwich College Suzhou, Suzhou, Jiangsu, 21502, China \\ *Corresponding author Email:1613187313@qq.com
}

\begin{abstract}
In recent years, several countries have reduced or exempted tampon tax, which aims to reduce tampon prices and eventually increase affordability. However, tax reduction or exemption do not necessarily lead to a price reduction, and the rate of change in price fluctuates dramatically among countries. This paper aims to explore why the tax reduction does not always lead to a price reduction in some regions.
\end{abstract}

Keywords: tampon tax reduction, tampon price change, empirical evidence

\section{INTRODUCTION}

\subsection{Definitions of three terms}

Period poverty is a global issue of being unable to afford hygiene products such as sanitary napkins, tampons or pads to control menstrual bleeding. Period poverty encompasses not only the inability to obtain hygiene products, but also inadequate access to toilets, hand-washing receptacles, and hygienic waste management. [1]

Tampon tax: the tampon tax is a value-added tax or sales tax that is imposed on female menstrual hygiene products by a government [2]. These are necessary items worn by a woman while she is menstruating, for examples: tampons, sanitary pad, sanitary towel etc.

VAT: A value-added tax (VAT) is a consumption tax placed on a product whenever value is added at each stage of the supply chain, from production to the point of sale. The amount of VAT that the user pays is on the cost of the product, less any of the costs of materials used in the product that have already been taxed [3].

\subsection{Background knowledge}

Tampon tax is a common tax, which exists in both emerging and developed countries. High tampon tax has been considered as a serious issue, because sanitary products are necessities, which means that the demand of sanitary products in the market will always maintain colossal no matter how high the price is. A relatively high tax levied on female sanitary products makes it even harder for people who can barely meet their basic needs to afford.

Globally, many countries are prohibited from creating zero-rated value-added taxes on period products, and some even impose high rates of tampon tax. People living in poverty already face barriers to obtaining menstrual hygiene supplies and related health services. With the rising costs and growing economic uncertainty, they now face even greater obstacles. As a result, in numerous countries, a high percentage of females miss school or work during their menstrual cycle, and many even drop out completely once they begin menstruating.

After years of activists campaigning and protesting against the discriminatory fee for menstrual products, some countries have managed to reduce or eliminate the tampon tax. A number of countries, such as Australia, German and Greece have either reduced or exempted the tampon tax. To illustrate, the UK outlawed value-added tax on menstrual hygiene products starting from JAN.1.2021[4]. It has been considered a beneficial move by public as it has relieved the burden on female in terms 
of finance. The UK Chancellor Rishi Sunak said that he was proud that the UK is delivering on its promise to scrap the tampon tax [4]. Since sanitary products are essential, not charging VAT can be considered as a beneficial behavior.

\subsection{Problems}

Although the intention of removing or reducing VAT/sales tax on sanitary products is to benefit the public, the resulting prices turn out to be different among countries. For example, after the exemption of the $6.9 \%$ sales tax on menstrual products, retail prices dropped by $7.3 \%$. And the prices reduction was disproportionately between different income groups, with $3.9 \%$ reduction in price experienced by high-income women, and $12.4 \%$ by the low-income women [5]. Nevertheless, the results were different after the VAT/sales tax exemption in Tanzania on 1 July 2018. The government states that the exemption results were far from exception and during the eleven and a half months in which pads were exempt from VAT, the reduction in prices is hard to notice $[6,7,8]$. This paper is aimed to explain why the price does not always decrease by the decline of tax, and what are the possible factors.

\section{LITERATURE REVIEW}

In recent years, some countries have exempted tampon tax (VAT and sales tax) in order to reduce tampon prices and thus relieve period poverty. However, the resulting tampon price does not meet. the expectation that a price reduction does not show up in every region. For instance, the prices of tampons in Zimbabwe surprisingly increase by $800 \%$ [9] after the exemption of VAT in 2018. Based on studies on VAT/sales tax and our own knowledge, three hypotheses are proposed to explain this phenomenon.

Hypothesis 1: Whether the country is developed or not would be a factor.

According to Myint $\mathrm{H}$, most emerging countries are lagged in per capita income, rate of economic growth, and consumption level. Compared to developed countries [10] differences in economic levels would influence the efficiency of economic policies (tampon tax exemption policies in this scenario), considering consumers' purchasing behavior is based on their economic conditions[11]. Therefore, difference between developed countries and developing countries is considered as a key factor.

Hypothesis 2: Inflation rates would affect the change in price after a tax reduction.
Inflation is defined as a general rise in prices of goods and services of an economy over a period of time [12]. Inflation causes the domestic price of goods and service to increase, leading to increase in prices of tampons. Inflation also causes domestic currency to depreciate, which indicates more cost when importing raw materials or commodities from foreign, especially for some developing countries that lack materials like cotton and their own tampon brands. In this way, reduction in prices caused by tax change will probably be counteracted by the increase in price entailed with inflation.

Hypothesis 3: Market structure would lead to a nonchanging or increase in price when a tax reduction appears.

According to Copenhagen Economics (2007), tax reduction is passed thoroughly through to consumers in a perfect competition market, that is, price reduction, as fierce competition induces companies to set the lowest prices to maximize profit [9]. On the contrary, in a less competitive market, an alteration in tax would not impute to consumers completely in a short or medium term. Clearly, in this scenario, market structure greatly influences how tax changes affect prices.

\section{DATA AND METHODOLOGY}

In order to test whether the three possible factors (developed/developing countries, inflation rate, market structure) are correct, data on tampon tax reduction rates, tampon price reduction rate, inflation rates and market concentration rates from New Jersey (USA), Illinois (USA), Australia, Canada, Spanish, Germany, UK, China, Tanzania, Zimbabwe, India, Kenya is collected.

In order to test the first hypothesis, data from both developed countries and developing countries are selected. As for the second hypothesis (inflation rates), data from the year that the tax is reduced and the year after are collected. Since it takes time for the market to adjust the prices, and a lag in time may be exist while collecting data on prices, 2 years' inflation rates of 11 countries are collected. When it comes to the third hypothesis about the market structure (more tend to be a monopoly or perfect competition), the sum of market share of the top four companies in the Sanitary Paper Product Manufacturing industry from different countries are collected. It is acknowledged that the greater the sum is in a country, the more concentrate the industry is. Thus, the market is more likely to be a monopoly. In contrast, the smaller the market share of the top four companies is, the more possible for the market to be a perfect competition. 
Table 1. Regression models will be used to illustrate the association between the two variables.

\begin{tabular}{l|l|l|l|l}
\hline Developed countries & Price reduction & tax reduction & Inflation rate & inflation rate in the following year \\
\hline New Jersey & 7.3 & 6.9 & 3.9 & 3.6 \\
\hline Illinois & 6 & 6.25 & 1.26 & 2.14 \\
\hline Austrualia & 9.1 & 10 & 1.61 & 0.87 \\
\hline Canada & 2 & 5 & 1.13 & 1.43 \\
\hline Spanish & 5 & 6 & 1.68 & 0.7 \\
\hline Germany & 10.5 & 12 & 0.37 & 3.8 \\
\hline UK & 2.3 & 5 & 1.53 & 1.67 \\
\hline Developing countries & & & & \\
\hline Tanzania & 0 & & & \\
\hline Zimbabwe & -800 & 18 & $3.51-2.45$ & 3 \\
\hline India & 0 & $20-30$ & 10.61 & 255.5 \\
\hline Kenya & $16($ by most) & 12 & 3.95 & 4.76 \\
\hline China & -4.2 & $4 \%$ & 11.6 & 10.31 \\
\hline
\end{tabular}

\section{EMPIRICAL EVIDENCE}

To study the correlation between the tampon tax reduction and tampon price reduction, as well as the correlation between the tampon tax reduction and the inflation rate, the term correlation coefficient would be used. Correlation coefficient is used to measure how strong a relationship is between two variables. If the value of $r^{2}$ (correlation coefficient) turns out close to 1 , then there is a strong linear association between the VAT reduction and the price reduction. If the value of $r^{2}$ turns out small, then there is not a significant association between the two variables.

The p-value is the probability of obtaining results at least as extreme as the observed results of a statistical hypothesis test, assuming that the null hypothesis is correct. The p-value is used as an alternative to rejection points to provide the smallest level of significance at which the null hypothesis would be rejected. A smaller p-value means that there is stronger evidence in favor of the alternative hypothesis.[14]

\subsection{Potential factor: Developed country VS Developing Country}

The first possible cause is whether the country is developed country or not. To demonstrate the hypothesis, the following data is collected:
Table 2. tampon tax reduction and consequent price change in certain regions

$\begin{array}{lll}\begin{array}{l}\text { Developed } \\ \text { countries }\end{array} & \begin{array}{l}\text { Price reduction } \\ (\%)\end{array} & \begin{array}{l}\text { Tax } \\ \text { reduction } \\ (\%)\end{array} \\ \text { USA, New Jersey } & 7.3 & 6.9 \\ \text { USA, Illinois } & 6 & 6.25 \\ \text { Australia } & 9.1 & 10 \\ \text { Canada } & 2 & 5 \\ \text { Spain } & 5 & 6 \\ \text { Germany } & 10.5 & 12 \\ \text { UK } & 2.3 & 5 \\ \text { Developing countries } & \\ \text { Tanzania } & 0 & 18 \\ \text { Zimbabwe } & 800 & 25 \\ \text { India } & 0 & 12 \\ \text { Kenya } & 16 & 16.7 \\ \text { China } & -4.2 & 4\end{array}$




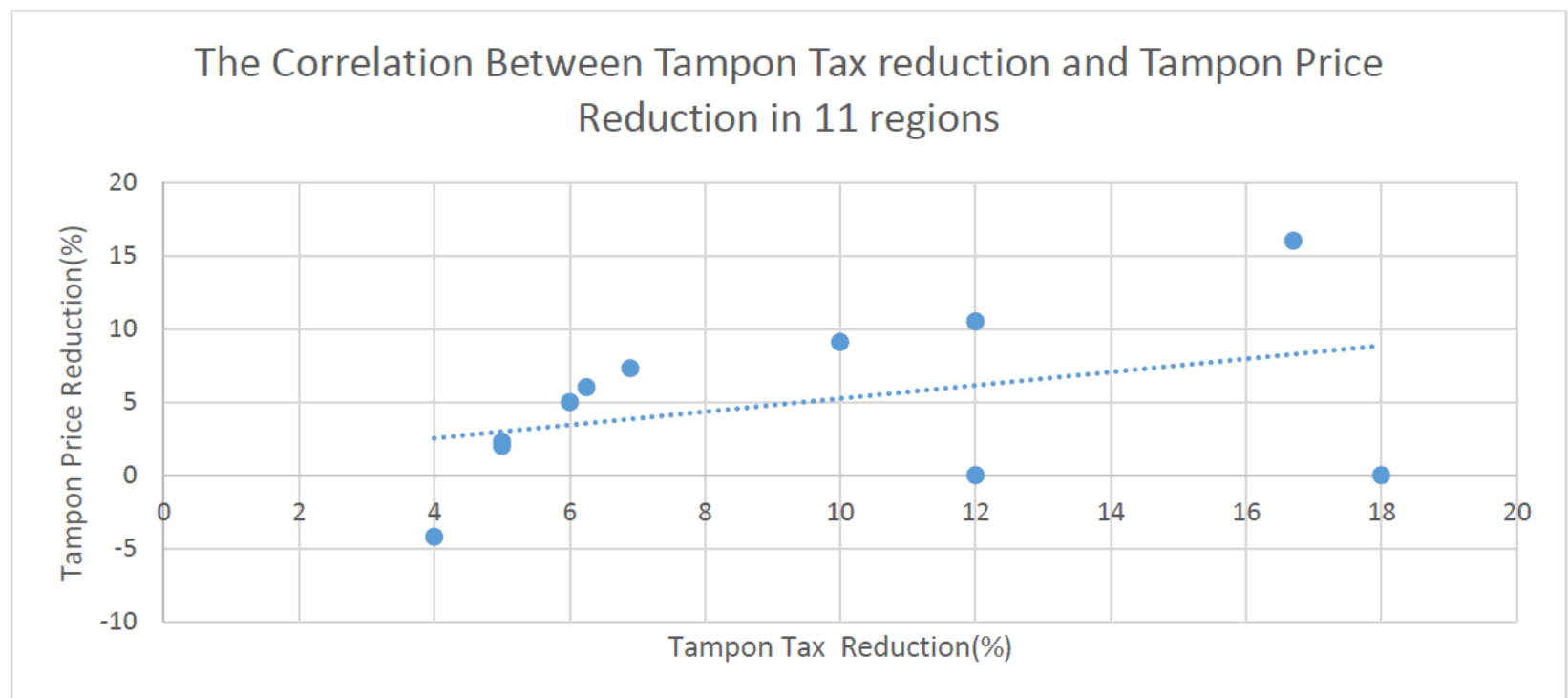

Figure 1 correlation between tampon tax reduction and consequent price change in 11 developing and developed regions

Figure 1 illustrates the scatter plot of the data given in Table 2. The correlation coefficient is approximately 0.022. Therefore, no association between tampon tax reduction and tampon price reduction is shown. The correlation between the two variables was not strong enough to state that a reduction in tampon tax would necessarily lead to a decline in tampon price in all regions in the world. Meanwhile, the $\mathrm{p}$ value is extremely high, 0.497 to be more specific, which again demonstrate that there was not a direct relationship between tax reduction and price decline.

Nevertheless, the result turns out differently when only plot the data from developed countries:

\section{The Correlation Between Tampon Tax reduction and Tampon Price Reduction in 7 developed regions}

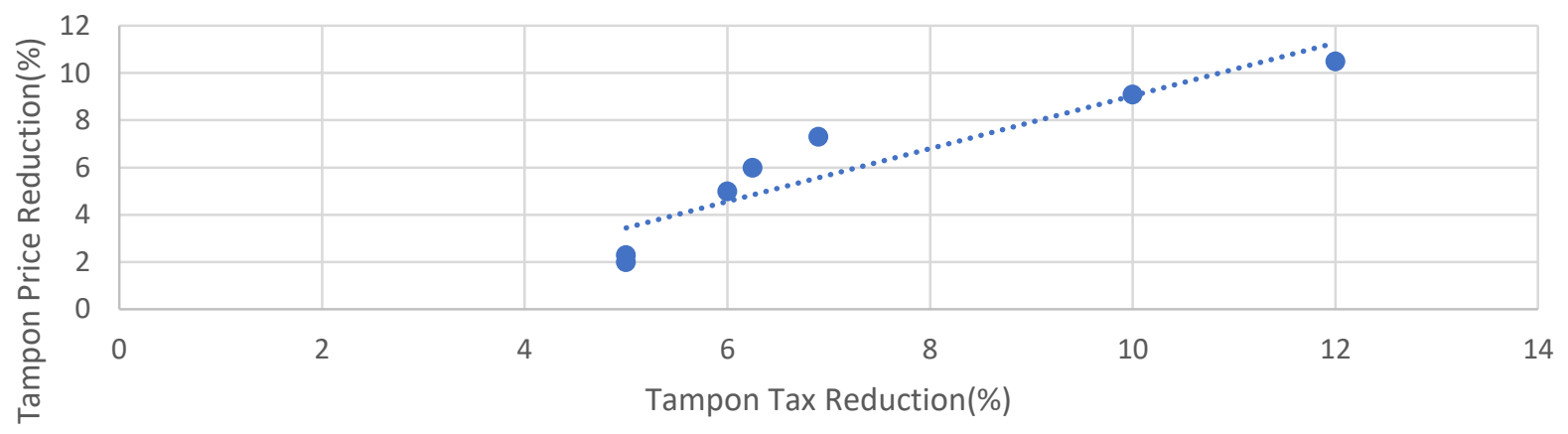

Figure 2 correlation between tampon tax reduction and consequent price change in 7 developed regions

The correlation coefficient is approximately 0.917 , which is very close to 1 . Thus, there is a strong positive linear association between tampon tax reduction and tampon price reduction in developed countries. Moreover, the $\mathrm{p}$ value in this case is approximately 0.003 , which states that the hypothesis is convincing.

\subsection{Potential factor: Inflation}

Inflation is a typical measure of the rate of increase in price over a given period of time. It affects the cost of living, running a business, borrowing money, and many other aspects of a economy[15]. Specifically, production activity is greatly influenced by inflation rate because 
many companies are operated worldly, and their daily production involves imports and exports. As inflation reduces purchasing power of some consumers, and erodes the real value of money, real prices of goods within the market would change. However, prices change at different paces. Some, such as the prices of traded commodities, change every day; others, such as wages stipulated in contracts, take longer to adjust. And when it comes to sanitary products, different countries have adopted different measures on price adjustments against inflation.

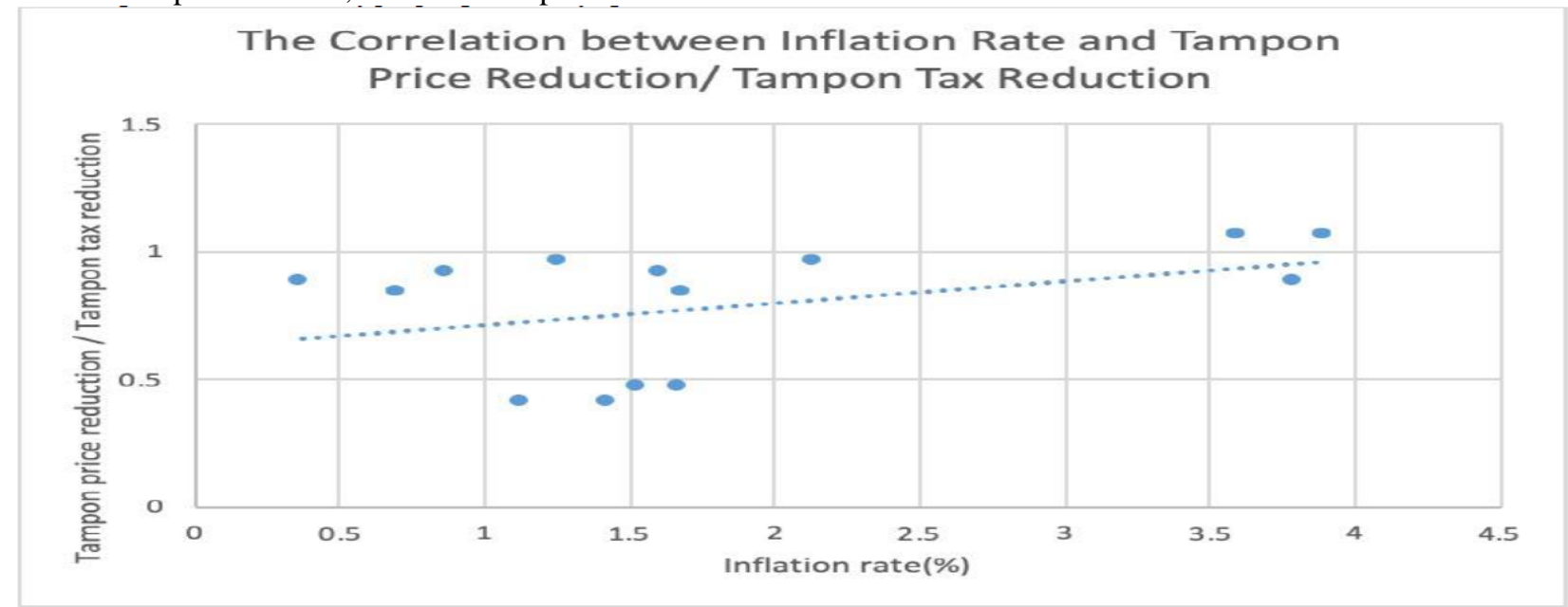

Figure 3 (correlation between inflation rate and tampon price change rate per tax reduction rate)

Generally, tampon price reduction rate is increasing with higher inflation rates in all of the 11 regions, and the graph presents a slightly upward sloping trend, indicating a positive but weak correlation between the two factors within those regions.

However, when we fit a regression line through the cloud of data points, the real observation might not fall exactly on the regression line. We can see that the data contains quite a large amount of variability. The distance between the regression line and the data point represents the unexplained variation, which is also called the residual. We therefore uses the method of least squares to minimize the residual[16] Now that we get the key measure to the validity of the estimated linear line, $\mathrm{R}^{2}$, which is approximately 0.0765 . This means that only $7.65 \%$ of the total variance is explained with the relationship between tampon price reduction and the rate of inflation. In this case, since the value of $r^{2}$ is very close to 0 , we can say that the independent variable (inflation rate) have nearly no influence on the dependent variable (rate of tampon price reduction).

Based on the analysis above, no strong correlation is found between inflation rate and price reduction of sanitary products.

\subsection{Potential factor: market structure}

As the theory of the market structure states, the price tends to be lowest in a perfect competitive market, because of the similarity of the products and the bargaining power of buyers. All suppliers tend to set the lowest price in order to attract more consumers, and eventually maximize the sales revenue. Besides, in a monopolistic market, in order to maximize profits, producers would sell their products at the quantity where marginal price is equal to marginal revenue (price). Based on these theories, an extension is proposed by the authors: as producers set the lowest price that will not bring loss in a perfect competitive market, tax reduction would thoroughly pass on to consumers, whereas in a less competitive market, price reduction is partly passed on to consumers.

$\mathrm{CR} 4$, stands for four-firm concentration ratio, is a measure to quantify how competitive a market is. In this session, CR4 of sanitary products industry from the UK, the US and china are collected. 


\section{SANITARY PRODUCTS INDUSTRY IN THE UK-- MARKET SHARE DISTRIBUTION}

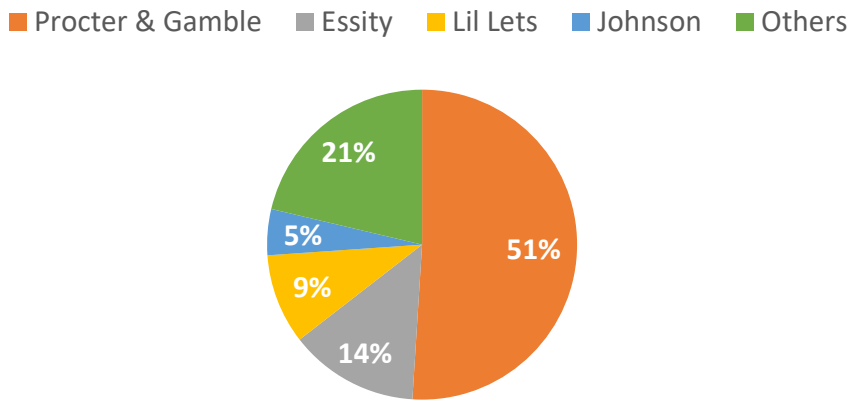

Figure 4 (maker share distribution of sanitary products industry in the UK)

\section{SANITARY PRODUCTS INDUSTRY IN THE US--MARKET SHARE DISTRIBUTION}

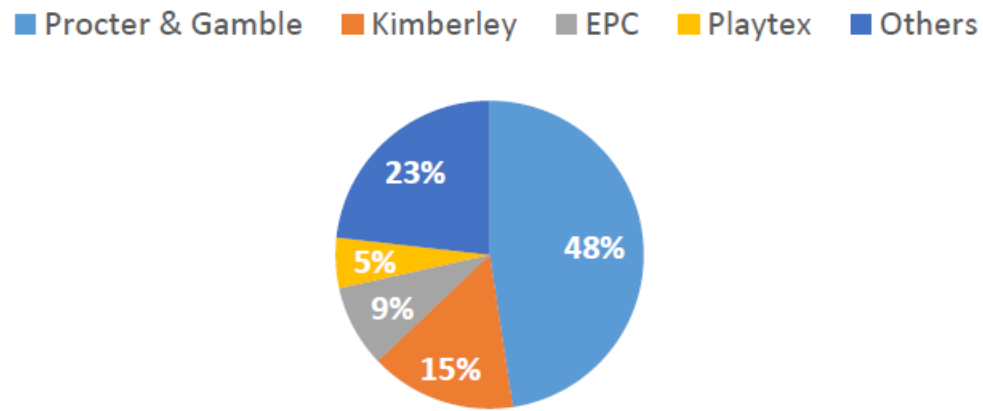

Figure 5 (maker share distribution of sanitary products industry in the US)

CR4 in tampon industry is $78.7 \%$ (Procter\&Gamble $51 \%$, Essity $13.5 \%$, Lil Lets $9.4 \%$, Johnson $5 \%$ ) in the UK and $76.8 \%$ (Procter\&Gamble $47.6 \%$, Kimberley $15.3 \%$, EPC $8.6 \%$, Playtex $5.3 \%$ ) in the US, indicates that both tampon markets in the USA and the UK are extremely oligopoly markets. ( According to American Economist Joe Bain, market whose CR4 is greater that $75 \%$ is a concentrated oligopoly.)

\section{SANITARY PRODUCTS INDUSTRY IN CHINA--MARKET SHARE DISTRIBUTION}

- Unicharm Hengan $\quad$ Procter \& Gamble Kimberly Others

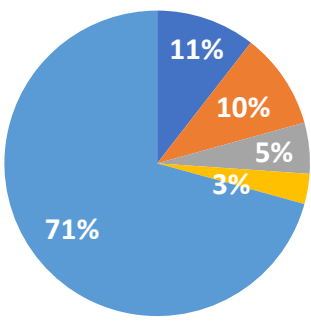

Figure 6 (maker share distribution of sanitary products industry in China) 
CR4 in tampon market in China in $29.3 \%$ (Unicharm $10.9 \%$, Hengan $10.2 \%$, Procter\&Gamble $5.4 \%$, Kimberly $3.2 \%$ ) by the time that tampon tax is reduced. Therefore, the tampon market in China is much more competitive compared with those in the UK and the USA.

Table 3. (CR4 and tampon price change rate per tax reduction rate in four regions)

\begin{tabular}{|l|l|l|}
\hline Regions & $\begin{array}{l}\text { Price reduction rate/ } \\
\text { tampon tax reduction } \\
\text { rate }\end{array}$ & CR4 \\
\hline China & -1.05 & $29.30 \%$ \\
\hline $\begin{array}{l}\text { New } \\
\text { Jersey( } \\
\text { USA) }\end{array}$ & 1.06 & $76.80 \%$ \\
\hline $\begin{array}{l}\text { Illinois(USA) } \\
\text { The UK }\end{array}$ & 0.96 & $76.80 \%$ \\
\hline
\end{tabular}

According to the hypothesis proposed, the closer CR4 is to 1 ( less competitive the market is), the greater the value of price reduction rate divided by tampon tax reduction rate would be. Nevertheless, China, whose tampon market is the most competitive ( lowest CR4)among the 4 regions, has the smallest alteration , which implies that, the change in price per percent of tax reduction is minimum ( in this scenario, tampon price even increases after tax exemption). This data challenges the third hypothesis because China, with lowest CR4 value, has lowest tampon tax reduction rate, opposite to the expectation that price reduction per tax reduction would be the highest in China. Thus, the hypothesis been made overturned.

The possible explanations would be firstly there may be other factors that has not been considered, for instance, nature of business( state-owned or foreign funds), the tariffs war and so on. Specifically, $\$ 500$ billion of Chinese goods are imposed high tariffs on by the USA in 2019, by which increased the cost of tampons and increased the tampon prices.

\section{CONCLUSION}

To address period poverty, many countries in the world have reduced or exempted tax on tampons so as to make tampons more affordable. Surprisingly, the extent that tampon price is changed fluctuates among regions. This paper aims to explore why the tax reduction does not lead to a price reduction in some regions. Three potential factors are proposed in the research: (1) developed or emerging countries, (2) inflation rate, (3) market structure.

The first conclusion is that whether a country is developed or emerging is a key factor which would influence the change in price after a tax reduction. By comparing the correlation of Figure 1 and Figure 2, it is observed that there is a strong positive linear correlation between tampon tax reduction and price reduction in developed countries, but not in developing countries. The second conclusion been drawn is that inflation rate is not a key factor. Inflation rates of 2 years from 11 regions are selected and then plotted in the scatter plot. After observing that $r^{2}$ is extremely close to zero, we concluded that inflation doesn't have a strong correlation with price reduction. The third conclusion is that market structure not necessarily have an impact on tampon price reduction rate caused by tax change. According to Table 2, China, who has the lowest tampon market's CR4 (the most competitive market) would have the greatest change in price per percent reduction in tax. The data that China actually has the lowest tampon price reduction rate per tax change refutes the previous prediction, and overturn the third hypothesis.

Because of the limiting access to some data, the conclusion made in the paper may not be that reliable. Besides, other potential factors that is not been discussed in this paper might exist. Hence, we sincerely invite more researchers focus on this research question--How tax reduction or exemption influence prices.

\section{REFERENCES}

[1] Kilpatrick, Ashley Rapp and Sidonie. "Changing the Cycle: Period Poverty as a Public Health Crisis.” U, University of Michigan School of Public Health, 4 Feb.

2020 ,

sph.umich.edu/pursuit/2020posts/periodpoverty.html

[2] D'Souza, Deborah. "What Is the Tampon Tax?" Investopedia, 15 July 2021, www.investopedia.com/tampon-tax-4774993

[3] Kagan, Julia. "What Is a Value-Added Tax (Vat)?" Investopedia, Investopedia, 27 July 2021, www.investopedia.com/terms/v/valueaddedtax.asp.

[4] Treasury, HM. "Tampon Tax Abolished from Today." GOV.UK, GOV.UK, 1 Jan. 2021, www.gov.uk/government/news/tampon-taxabolished-from-today.

[5] Cotropia and Rozema, 2018

[6] "Lessons Learned From Tanzania's Recent Menstrual Product VAT Flip Flop." IMHER.net, 1 Aug. 2019, imher.net/blog/2019/08/tanzania-vatflip-flop/.

[7] KMPG, Budget Brief Tanzania, 2019

[8] Healthtimes. "Mthuli Ncube Urged to Review Sanitary Wear Prices in Supplementary Budget." HealthTimes, 29 July 2019, healthtimes.co.zw/2019/07/29/mthuli-ncube-urged- 
to-review-sanitary-wear-prices-in-supplementarybudget/.

[9] Copenhagen Economics, "Study on reduced VAT applied to goods and services in the Member States of the European Union", 2007

[10] "Welcome to CAB Direct." CAB Direct, www.cabdirect.org/cabdirect/abstract/19746703104.

[11] Dijkstra, A. "The Effectiveness of Policy Conditionality: EIGHT Country Experiences." GSDRC, 1 Jan. 1970, gsdrc.org/documentlibrary/the-effectiveness-of-policy-conditionalityeight-country-experiences/

[12] Fernando, Jason. "Inflation." Investopedia, Investopedia, 27 July 2021, www.investopedia.com/terms/i/inflation.asp.

[13] Treasury, HM. "Tampon Tax Abolished from Today." GOV.UK, GOV.UK, 1 Jan. 2021, www.gov.uk/government/news/tampon-taxabolished-from-today.

[14] Beers, Brian. "What p-Value Tells Us.” Investopedia, Investopedia, 2 Aug. 2021, www.investopedia.com/terms/p/p-value.asp.

[15] Davis, Marc. "Inflation and Economic Recovery." Investopedia, Investopedia, 29 June 2021, www.investopedia.com/financialedge/0212/inflation-and-economic-recovery.aspx.

[16] 16."How to Conduct Linear Regression." Statistics Solutions, $\quad 29 \quad$ Apr. 2021,www.statisticssolutions.com/freeresources/directory-of-statistical-analyses/how-toconduct-linear-

regression/?_cf_chl_jschl_tk_=pmd_639e59da26 2dcee19dafa $\overline{2}$ aba40aa39550 ce 7985-1628144927-0gqNtZGzNAjijcnBszQei. 